Culture et histoire dans l'espace roman

$4 \mid 2010$

Les représentations du corps dans la litterature latinoaméricaine

\title{
Su cuerpo dejarán
}

La representación del cuerpo en la poesía cubana contemporánea

Félix Ernesto Chávez

\section{(2) OpenEdition}

\section{Journals}

Edición electrónica

URL: https://journals.openedition.org/cher/8534

DOI: $10.4000 /$ cher.8534

ISSN: 2803-5992

Editor

Presses universitaires de Strasbourg

Edición impresa

Fecha de publicación: 30 junio 2010

Paginación: 61-73

ISBN: 978-2-35410-007-0

ISSN: $1968-035 X$

\section{Referencia electrónica}

Félix Ernesto Chávez, «Su cuerpo dejarán», reCHERches [En línea], 4 | 2010, Publicado el 15 diciembre 2021, consultado el 27 enero 2022. URL: http://journals.openedition.org/cher/8534 ; DOI: https:// doi.org/10.4000/cher.8534

\section{cc) (ㅇㅇ (-)}

Ce(tte) œuvre est mise à disposition selon les termes de la Licence Creative Commons Attribution -

Pas d'Utilisation Commerciale - Partage dans les Mêmes Conditions 4.0 International. 


\title{
Su cuerpo dejarán. La representación del cuerpo en la poesía cubana contemporánea
}

\author{
Félux ERnesto Chávez \\ Universitat Autònoma de Barcelona
}

n la literatura cubana de las últimas décadas, el cuerpo - cada vez
más - ha devenido tema y objeto de la poética de los autores de las nuevas generaciones. Marcado por las circunstancias políticas, históricas y culturales del proceso revolucionario, el cuerpo se (re)presenta como la única posesión del individuo, a la vez que se identifica como el territorio de la realización personal, espacio de libertad y al mismo tiempo de sometimiento de voluntades y anhelos. Ya entrados los noventa del siglo pasado, el cuerpo alcanza nuevos significados con el advenimiento de las nuevas generaciones, nacidas y crecidas dentro del proceso revolucionario («hijos de la Revolución» serán llamados), pero surgidas en una etapa donde la literatura dejaba de asumir el sujeto de la colectividad, el recurrente «totalitarismo conversacional» (según Jorge Luis Arcos), el realismo socialista, el afán de destino común y justicia social imperantes en el discurso de los sesenta y setenta, para nutrirse de la experiencia de la literatura de los ochenta, y volcarse hacia el redescubrimiento del yo interior, de la persona individual, del valor del sujeto per se dentro de, ante y también sobre la sociedad misma. Mi interés en estas breves líneas radica en acercarme al corpus de la poesía cubana de las últimas décadas - fundamentalmente de finales de los 90 y principios del nuevo siglo -, para revis(it)ar voces de dentro y fuera de la Isla, que han convertido el cuerpo como eje de sus poéticas, desde la negación, hasta la aceptación y la anagnórisis. A tal 
efecto, asumo la generación del noventa como aquella que ha marcado/ predeterminado ciertas antologías poéticas (como Cuerpo sobre cuerpo sobre cuerpo o Heridos por la luz) y el ejercicio crítico en general - a través de prólogos o ensayos -, que establece aproximadamente a partir de 1970 las fechas de nacimiento de los creadores cuyas obras comienzan a desarrollarse - y publicarse - en los años noventa. Lo curioso de esta generación es que atiende más a una heterogeneidad discursiva, que intenta rescatar ciertas concepciones estéticas en cuanto a la forma, la vuelta de la tradición clásica (y también origenista), aunque debo hacer notar que la crítica sobre los noventa es más bien casuística, aún no sistematizada, probablemente por tratarse de voces demasiado cercanas en el tiempo y más propensas a un prejuicio historiográfico.

En este sentido, la generación poética que surge hacia los noventa se vuelca, dentro de su heterogeneidad discursiva, hacia la representación del cuerpo condicionado por las nuevas circunstancias histórico-sociales. Las "nuevas" variables dentro de la vida social cubana incluyen no sólo la escasez (de todo tipo) del llamado Período Especial, "instaurado" desde inicios de los 90, tras el derrumbe del campo socialista de Europa del Este, o la necesidad de un cambio ideológico que dicha desaparición implica dentro del contexto revolucionario; sino también el impulso de ciertos fenómenos que durante muchos años habían permanecido en la sombra del proceso revolucionario: la prostitución (sexual) como medio de vida, la visibilidad social del sujeto homosexual, la vindicación de cierto discurso religioso: en definitiva, la reafirmación y visibilidad de la "diferencia". Estos factores, que abrieron el abanico temático de la literatura en los noventa (no porque anteriormente no existieran, sino porque la mayor parte de estos temas no lograban burlar el cerco de la censura, o de otro modo, tenían que urdir complicadas estrategias discursivas para poder burlarlo), se unieron al rescate de la experiencia estética de escuelas rechazadas por el discurso oficial/oficialista de los sesenta-setenta: el grupo Orígenes en su casi totalidad; la literatura de Emilio Ballagas, Virgilio Piñera, José Lezama Lima y sus epígonos; la obra poética de Lina de Feria o Delfín Prats; el intimismo posmodernista de Dulce María Loynaz; la obra de Calvert Casey o Severo Sarduy ... aunque hay que reconocer que toda aquella literatura contestataria del sistema político imperante, donde se puede incluir a Reinaldo Arenas, el grupo de El Puente (1962-1964), Guillermo Cabrera Infante o Heberto Padilla, siguió "fuera del canon" impuesto por las autoridades. De igual manera, la pujante generación de los ochenta, cuya obra reanimaba y enriquecía el panorama de 
las letras cubanas, contribuyó al desarrollo de una visión poética más amplia, más abarcadora, y al mismo tiempo - e increíblemente - más introspectiva e inquisitiva, en los jóvenes creadores. Ya no sólo por la influencia del grupo Diáspora(s), que determinó un punto de inflexión cultural, sino por la misma labor de otros autores que, desde dentro del país o desde el exilio, ponían en tela de juicio esa normatividad ("conversacional", en muchos casos sometida a actualizaciones), en pos de la diversificación que profundiza en una variable de "desvío" que atraviesa la literatura de los ochenta y los noventa (bien desde una neovanguardia basada en la experimentación, bien desde un culturalismo, etc), y que ha analizado Walfrido Dorta.

Durante el Período Especial en Cuba, dos de los autores más interesantes - y probablemente las dos voces más "canónicas", aunque eso es algo que sólo el tiempo podrá corroborar y ya lo hace - acabaron con su vida por propia decisión, en plena juventud: Raúl Hernández Novás se suicidó a punta de revólver en 1993, y su amigo Ángel Escobar se arrojó desde el balcón de su séptimo piso, en 1997. A ambos les estorbaba una existencia que endureció sus parámetros y que hizo mella en su equilibrio psíquico (compartían el mismo psiquiatra). La poesía de los dos está atravesada por esas constantes que años más tarde también incidirían sobre una generación caracterizada por la huida, poética y material, una generación que intenté presentar/justificar en un texto anterior (Félix Ernesto Chávez 2008). El olvido, la imposibilidad (amorosa, social, existencial), el desarraigo, la falta de horizontes, la renuncia, el terrible desengaño, la fatalidad, los destrozos (materiales y espirituales) que circundan al sujeto, la imposibilidad de revertir el tiempo; todas estas son constantes que acercan a estos dos poetas con aquellos nacidos fundamentalmente a partir de 1970. Y también el modo de verse a sí mismos, la relación del sujeto con su cuerpo, su autoreconocimiento, toda vez que el cuerpo acoge esas inscripciones de dolor, de angustia, como depósito de esa misma fatalidad. El cuerpo entonces produce asimismo su propia necesidad de exterminio. En la raza de los suicidas, esto es algo que se ha estudiado en sus múltiples vertientes.

Curiosamente, la huida generacional que he planteado propicia una literatura basada en la representación del cuerpo como parte de un entorno cerrado, autárquico, íntimo, no expuesto como performance pública. Y, bueno es decirlo, asume como referentes inmediatos dentro de la tradición narrativa, textos como «Piazza Morgana» de Calvert Cassey; las novelas de Severo Sarduy y en especial las de Reinaldo Arenas; La carne de René, de Virgilio Piñera; sin obviar Paradiso, de Lezama. 
Existe, pienso, un momento importante en el surgimiento de la poética de los autores que comenzarán su obra sobre todo a mediados de los noventa: en 1989, en la revista El Caimán Barbudo, Norge Espinosa publica uno de esos poemas que marcan para siempre a un escritor (por la repercusión mediática que tuvo dentro de la Isla, debido al desenfado en el tratamiento de un tema - casi - tabú), "Vestido de novia». Como una performance privada, el "muchacho de manos azules" que se viste de novia, establece un diálogo de identidad con su propio cuerpo. Cada acto de ese muchacho se revela como una crisis, y al mismo tiempo como un anhelo de visibilidad. Su posibilidad queda anulada por la ausencia de ojos y espejos que "miren" la realidad que él está viendo. Es ese cuerpo "vestido" el que está exigiendo una nueva inscripción, que no existe por temor a lo proscrito, y quizás al rechazo social (probablemente instalado ya en sus propios mecanismos de razonamiento):

Quién

le va a apagar la luz bajo la cama y le pintará los senos con que sueña quién le pintará las alas a este ángel mal hecho para las burlas si a sus alas las condenó el viento y gimen quién quién le va a desvestir sobre qué hierba o pañuelo para abofetearle el vientre escupirle las piernas a este muchacho de cabello crecido así vestido de novia.

Con qué espejos

con qué ojos

va a retocarse las pupilas este muchacho que alguna vez quiso llamarse Alicia que se justifica y echa la culpa a las estrellas.

Con qué estrellas con qué astros podrá mañana adornarse los muslos con qué alfileres se los va a sostener con qué pluma va a escribir su confesión ay este muchacho vestido de novia en la oscuridad es amargo y no quiere salir no se atreve no sabe a cuál de sus musgos escapó la confianza no sabe quién le acariciará desde algún otro parque quién le va a dar un nombre con el que pueda venir y acallar a las palomas matarlas así que paguen sus insultos.

[...]

Está perdido en un encaje y no tiene tijeras

Así vestido de novia como un pacto hacia el amanecer.

A pesar de que Espinosa intenta desmarcarse de sus colegas generacionales, puesto que él se ve más afín a la generación de los ochenta (en la línea de Damaris Calderón, principalmente), su estilo e imaginario poético son, en 
mi criterio, más próximos a los de los poetas que comenzarían su andadura pocos años después. Su muchacho "vestido de novia" constituirá uno de los puntos de apoyo del abordaje temático del sujeto homosexual, y sobre todo, se erigirá como texto paradigmático de un cambio en cierta visibilidad cultural, que se vio apuntalado también por el cuento de Rolando Urías "¿Por qué llora Leslie Caron?» y el éxito internacional, un año más tarde, del relato El lobo, el bosque y el hombre nuevo, de Senel Paz.

Casi toda la poesía de la segunda mitad de los noventa aborda esta sensorialidad del cuerpo, y su conflicto identitario. En la mayor parte de los textos, la preocupación (como angustia de identidad) no existe, o es trascendida por la representación. O se establece una línea de ambigüedad en función de un valor sensual. Existe una zona de esta representación que se decanta hacia lo religioso (Liudmila Quincoses); otra tiene una connotación abiertamente homoerótica (José Félix León, George Riverón, Norge Espinosa); otra se vale de un discurso vindicativo (la obra primera de Aymara Aymerich); otra explora en nuevos campos poéticos donde la poesía linda con la prosa, y se abisman sistemas y variables en continua transformación, como en la poesía de Javier Marimón. La moralidad deja de existir en estos textos. Porque en el discurso de esta joven generación, el cuerpo forma parte del conjunto, no está aislado del devenir y no está "prejuiciado" (aunque sí "motivado") por las variables externas. Las marcas que exhibe el cuerpo forman parte de las marcas de la propia personalidad, representa la prolongación del yo, la exteriorización de un componente íntimo, que dialoga con la realidad, que vehicula el deseo, el impulso nervioso o carnal, pero también proyecta la necesidad de cambio, de impregnar de un significado que los separe de ese "valor común" que los asemeja a aquellos (otros) que los rodean:

La function ha atravesado la escenografía hacia la realidad más inmediata: el descubrimiento excesivo de mi situación en la vida u otro dato común que alcanza una sutil emoción. Arrojar un valor en la function. \& estos cuerpos aquí, distrayéndome de la exigente obra que debo representar al Impulso. Los idiotas cuerpos de mi familia: la facilidad patológica de la quietud. Impulso, sólo a ti me confío (hacia el culito). Sólo tú debes martirizarme \& poseerme. Seré tu chica. Sepárame de estos cuerpos lejanos. Atraviesa con violencia el punto infame de mis estados morales. Penétrame como a tu mejor chica. A ti me confío \& obedezco. (Javier Marimón, «Procedure / Function»)

Hay otro componente que se hace visible en la obra de estos autores, y es la insularidad, esa "maldita circunstancia del agua por todas partes», al decir de Virgilio Piñera. Hay un interesante poeta, Nelson Simón - cuya 
poética se me hace familiar con la de esta generación, aunque es algunos años anterior - que convierte el cuerpo como representación de un "algo" en estrecho contacto con el destino de la nación, integrándolo como parte indispensable de la identidad nacional. Por una parte, por las propias condiciones del país: una isla donde "salir" es ya un desafío, y que opera como trampa ("esta isla es una trampa", diría el personaje de Sergio en Memorias del subdesarrollo de Tomás Gutiérrez Alea, basada en la novela homónima de Edmundo Desnoes.) Una isla que opera como una gigantesca cárcel donde cabe la angustia, la asfixia, la respiración en el cristal. Y al mismo tiempo el país como dolor (incluso a la manera de Cristo), algo que marca físicamente, como en «El peso de una isla», de Nelson Simón:

Y ahora que llevo mi país

como quien lleva una corona de espinas

hiriéndome la frente,

es mi país el sitio más querido,

también el más odiado,

es el ruedo de muerte, es la desesperanza,

otro golpe de mar, su inminente presencia

en el dolido pecho

de aquellos que como pájaros tropicales

se alejan de sus costas

en busca de otras costas más íntimas [...]

Curiosamente, también Norge Espinosa será uno de los poetas que conducirán esa representación del cuerpo en comunión con el simbolismo de la nación, cuerpo como testigo del devenir nacional, cuerpos testimoniantes de/ante la muerte de "algo", ya desexuados y en apariencia ambiguos:

Años más tarde, vería un álbum de fotos firmadas por Giorgio:

ángeles de piedra en el Cementerio de Colón.

Me extrañó no hallar en ese álbum nuestros rostros.

Qué tumba del país velábamos entonces.

Yo abrazaba a Vladimir. También, es cierto, lo engañaba.

Él jugaba el mismo juego. Como ángeles de piedra,

sentíamos la felicidad. («Marlene Dietrich: Peter»)

Es esa misma muerte la que revela "otras caras" del cuerpo, y el cadáver como símbolo de un país, de una ideología, de la esperanza misma (Félix Hangelini 2006). La misma relación con la muerte que hace hablar a los poetas de esta generación como huérfanos de un yo, que o bien se ha quedado anclado en la realidad que les circunda, o bien en ese pasado que ha quedado o han dejado atrás, como cuando Carlos Pintado nos revela en 
«Lectura de cartas»: «Vástago soy de un cuerpo temeroso, / De una sombra que muere en otra sombra». Casi la misma afirmación (ésta última, más rotunda) que realiza José Félix León en "Correos / bosques intermedios»:

Estamos muertos. Pasan

peces volando y se persiguen

suaves trasmutaciones

en la cáscara del universo.

$\mathrm{Al}$ amanecer el farero se despide

y la isla da una idea de infinito.

Dormimos en la costa. Los ahogados

acercan sus ojos mordidos por los peces

y soplan la estructura endeble

del velero entre las rocas.

Es la hora de la calma

y el silencio del amor.

Estamos muertos.

En esencia, son tiempos en los que el incierto destino nacional condiciona la mirada del sujeto: la visión del que "se va" y la del que "se queda" se convierten en dos perspectivas distantes y limítrofes (pues comparten un objeto) y al mismo tiempo interdependientes en la comprensión de la realidad "total", por llamarla de algún modo. Y también es una época donde la destrucción física del país encuentra ecos en esa pérdida latente y constante, y en la desintegración misma del sujeto poético. Cuando José Luis Fariñas escribe «Ya puedes respirar porque ya puedes volver,/ y la carne del retorno es inviolable», insiste en cierto modo también en esa doble identidad que "gana" el exiliado, a costa de la pérdida del arraigo original y del poder legal de residir "dentro". Esa dicotomía dentro/fuera, irse/quedarse, donde siempre "se pertenece", marca no sólo el discurso literario, sino también la vida política y cultural de la nación. Es la misma que atraviesa toda la realidad por ejemplo, de los balseros (no sólo de los noventa) y de los emigrantes (exiliados o no), estigmatizados, categorizados como tales por el poder fáctico.

Otro de los aspectos relevantes en el tratamiento del cuerpo es la forma en que deviene objeto de goce, de disfrute, estético y sensorial. Pienso que este disfrute es una forma de reacción contra ese Poder, una vez que lo ignora y/porque no lo teme. De ese modo, lo está negando, o al menos está negando la voluntad de obediencia, aunque paradójicamente reconozca el sometimiento. Ya no existe, o al menos ya no se evidencia, ese temor del «muchacho que se viste de novia». El nuevo sujeto desea, y asume al 
cuerpo como objeto de ese deseo. Incluso de forma irónica y vehemente, como apunta Aymara Aymerich en "Sobre un tema anglosajón», de su polémico libro in útero (2000): "viólame, amigo, y lloremos por la patria o el amor». Pero también acoge una necesidad que encuentra una barrera, una disonancia entre gesto y palabra, entre acción y verbo:

Obstáculos entre: el gesto y la palabra, mi pregunta y yo fluimos malolientes desde el útero que es un lugar indivisible como celda, que es un lugar donde mi única pregunta lo cuestiona todo.

Allí prefiero elegir nuestra distancia que es la mudez del condenado, que es un silencio donde me escupe y me ennoblezco.

Obstáculos entre: el gesto y la palabra, mi única pregunta y yo tenemos una letra más veloz que antes una paciencia más veloz y menos tiempo.

(Aymara Aymerich, «el útero es un lugar pequeño, es un lugar y es un silencio»)

O como también dice Michael H. Miranda en «Nada cura el hambre de decir»:

qué idea dibuja el cuerpo de fumar tendido

el tubo la probeta aquel olor en el pelo la ropa de cinco pm al mediodía ¿escriben algo como eso? ¿escribe alguien eso?

El discurso de la generación de los noventa se reafirma "sobre" el cuerpo, se vale de él, lo utiliza, lo asume, se autorreconoce, aunque su objetivo no es la exhibición pública intencionada. Pero lo importante es esa vivencia corporal que participa de la expresión poética, ese desenfado a tono con los terrenos conquistados, y que en la poesía han llegado más tímidamente que en la prosa (pienso por ejemplo, en Pedro de Jesús, Joel Cano, Ena Lucía Portela, Pedro Juan Gutiérrez, Zoé Valdés, Mayra Montero).

Hay una línea erótica, valiente, que recupera las zonas de poesía homosexual dentro de las coordenadas generacionales. Los dos ejemplos más connotados son, en mi opinión, José Félix León y George Riverón. Hay una ascendencia kavafiana, cernudiana, y hasta ballaguiana, en la 
poesía de ambos. En el caso de Riverón, la imagen del cuerpo "significa” en paisajes, estructuras naturales, con un tono a veces neorromántico, a veces sentimental, pero casi siempre con un trasfondo ciertamente religioso:

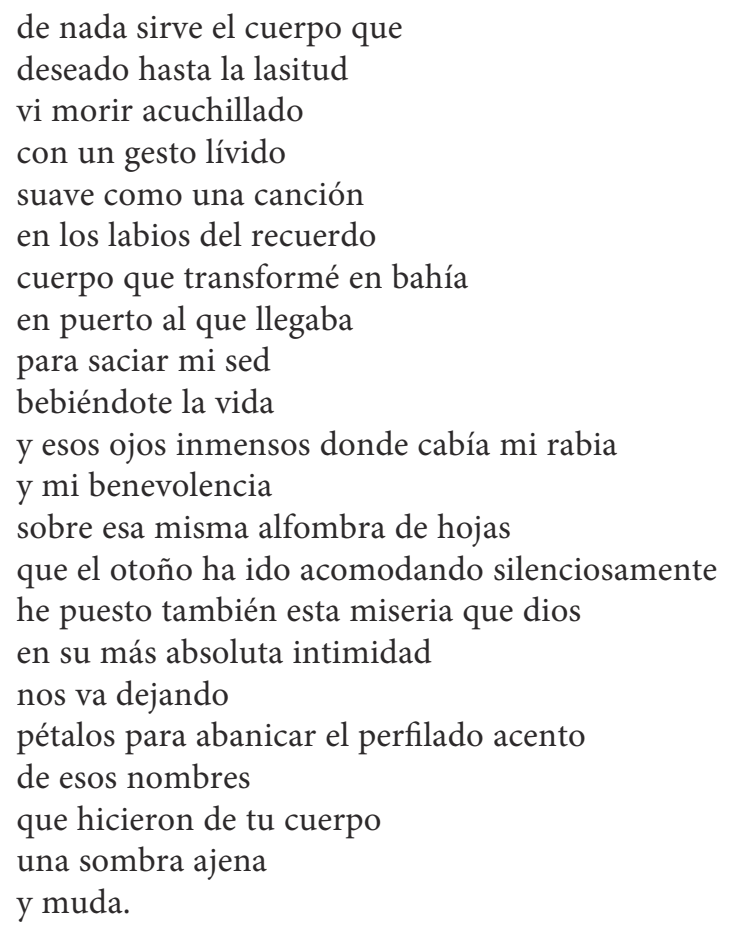

Esta religiosidad no se asemeja al tono profundamente religioso de Ludmila Quincoses, quien percibe el cuerpo como templo: "No me abandona este cuerpo, / torcido como una raíz venenosa / que nadie se atreve a cortar» (Ludmila Quincoses, «Luz y progreso»); o cuando escribe «Desde que sé tu nombre lo escribo sobre el agua, / porque de agua es tu cuerpo/ y tus ojos son agua». La línea que sigue Riverón, sin embargo, tiene asideros en los discursos de grandes artistas polémicos, que asumen su poliédrica visión del cuerpo como ejes temáticos; es el caso de Egon Schiele o Allen Ginsberg. En dos textos memorables, Riverón homenajea a estos autores, de los que extrae esa experiencia vivencial sobre el erotismo y la sensualidad, con tono kavafiano, donde se mezcla lo prosaico, lo cotidiano, lo carnal y la belleza de la perfección de las formas, así también lo lúdico y lo prohibido.

$[\ldots]$ sus modelos joven schiele me recuerdan cirios encendidos vírgenes de medianoche 
alucinadas por los brillantes lumínicos

en las puertas de los clubs

esos lugares donde los jóvenes soldados

ofrecían la mitad de sus sueldos

(centavos ganados rigurosamente)

por una jarra de cerveza amarga

y la fugacidad de un instante de placer [...]

(George Riverón, «a egon schiele»)

O cuando escribe :

hoy no tengo más que este disfraz de hombre

para asistir a tu llegada

un pañuelo de aguaceros

para escurrir los hermosos girasoles

que desprendes de la voz

$\mathrm{y}$ un ojo maldito

por el que miro cuán duros fueron tus anhelos

yo soy de los que desnudaron sus ángeles

angustiados moribundos consumidos

por el frío y la asfixia de la droga

ah si yo tuviera

cómo devorar el fuego de la carne

y fundirme con él bajo la noche inmensa

[...]

si yo tuviera amigo allen

dónde acurrucar mi cuerpo

dónde echar a arder mis huesos e improperios

dónde cavilar con mi cabeza de animal fantasma [...]

(George Riverón, «aullido por allen ginsberg»)

En un texto de José Félix León, «Figura de atleta, siglo V a.C.», el cuerpo se convierte en fabulación, en piedra fabulada por la reconstrucción de un pasado inalcanzable ya, sometido a la imposibilidad, al olvido, y también a la idealización, al tiempo que anuncia un hallazgo, siglos después, aunque ese hallazgo pase a ser secundario en el discurso mismo del texto:

Detrás de cada piedra bulle el mar,

la espuma que minuto a minuto he desgajado.

Mi amigo vuelve la cabeza y habla de su madre,

mi mano y la mano de mi amigo

son esas aves que lamen la distancia.

Debimos encontrarnos al bajar los escalones,

pero el mar no es mi cuerpo

ni el cuerpo de mi amigo. 
Debí esculpir el mármol, sus músculos untados con aceite, la espalda que se abre ahora junto a la roca.

En la plaza, a la salida del teatro, en los bosquecillos que rodean la acrópolis me encuentro con mi amigo.

En la palma de su mano queda un óbolo tibio como el ala de un pájaro.

Nadie lo recordará en los tiempos futuros, nunca encontrarán la estatua que labré y ahora lanzo a las aguas.

Nunca su rara laxitud, sus brazos provistos de la elegancia de la acción. Nunca la historia de su vida, vida que edifiqué y debí cegar con las mismas manos.

José Félix León rescata las tradiciones clásicas helénicas, ya intuidas en la poesía de Abilio Estévez y su Manual de las tentaciones. El elemento "fuga" alcanza en su poesía los ecos de una Grecia sensual y artística, donde como en un cuadro, todo acontece de modo anecdótico, en pinceladas, donde se congela el tiempo para mostrar un fragmento de la realidad completamente atemporal. También el espacio creado es atemporal, mezcla de herencias culturales clásicas con paisajes exóticos e insulares. Las fricciones entre cuerpo y realidad originan un juego continuo de interacciones donde el sujeto se recoloca en un espacio de angustia, pero sin cuestionamiento social, actitud esta que determina y define la posición del sujeto en el texto:

Lesiones:

en la cavidad del vello y la zozobra

de un estado que arrasa el ánimo

y la razón,

lesiones en el pubis.

El agua de la fuente pesaba, su cuello surcado de estigmas y cortes reclama un año de dolor.

Fluidos que no comprenderé, así vi el cuerpo de los novios.

Desde entonces padezco una ansiedad que me hace hostil a ese dominio, la sangre 
y la saliva matinal sobre sus caras.

(José Félix León, «Novios»)

No existe un deseo de instaurar universos, sino de restaurarlos. Todo lo que dinamitó la generación anterior, se intenta rescatar, sobre todo desde las lecturas de los clásicos (los más contemporáneos, o los antiguos). La identidad del sujeto se mueve en terrenos resbaladizos, como la existencia misma que acompaña al cuerpo o es acompañada por éste. El descentramiento característico de esta generación origina diversos modos de acercarse al cuerpo, desde el rechazo original que la propia sociedad promovía, hacia una comunión y aceptación que hace que el cuerpo se recoloque en el mismo plano que la personalidad, sin importar la forma misma corporal, o su identidad sexual.

Lo más curioso es ese sentido de "ausencia" - colindante con la sensación de "nada" - que revelan muchas de estas páginas, y que se transportó a la vida misma: es una generación que "no existe" ahora mismo dentro de Cuba, que ha generado un vacío por el éxodo, como ocurrió con gran parte de la generación del ochenta. Pero a diferencia de la que abordo, la de los ochenta - y a pesar de las carencias del país - logró más cohesión, más respeto intelectual y fue vista y analizada más como "grupo". La diseminación de los poetas de los noventa - casi todos los que he mencionado aquí participan del exilio - y su desvío / descentramiento (temático, estilístico) no pueden obviar el hecho de que lo que los reúne en su grupo generacional, más allá de unas cuantas fechas cronológicas, es una experiencia común, un desencanto común. Salvo casos aislados (pienso en algunos textos de Luis Manuel Pérez Boitel), el proceso revolucionario ha desaparecido del discurso poético, o se ha convertido en algo ajeno, incidental. En un país que vio resurgir, paulatina y públicamente, el cuerpo como un valor de mercado, como siempre lo fue de expresión y forma de identidad, los grandes temas de los noventa fueron/han sido/están siendo abordados desde un prisma reflexivo donde el sujeto se recoloca nuevamente en esa realidad, a la par que indaga sobre su rol, sobre su desesperanza, sobre su necesidad de caminos. Por supuesto, el exilio en ellos ha cambiado significativamente el modo en que perciben la realidad, las trampas han variado y la nostalgia se apodera de gran parte de los discursos; mas no ocurre así con el modo en que asumen el cuerpo. Existe, pues, una línea de hermanamiento en esa orfandad y esa andadura, desde donde nos dice George Riverón:

apenas soy un pasajero

pero en cada estación 
voy dejando un pedazo de mis carnes

un sueño que conduce a la agonía

trampa donde pierdo los ojos

para regalártelos hermano.

\section{Bibliografía}

AAVV, Cuerpo sobre cuerpo sobre cuerpo, 2000, La Habana, Letras Cubanas.

AAVV, 2001, Los parques. Jóvenes poetas cubanos, Cienfuegos, Ediciones MecenasReina del Mar Editores.

Arcos, Jorge Luis, 1995, “¿Otro mapa del país? Reflexión sobre la nueva poesía cubana”, en: Temas, La Habana, núm. 3, págs. 121-129.

Aymerich, Aymara, 2000, in útero, La Habana, Ediciones UNIÓN.

Aymerich, Aymara, 1999, Las palabras son islas. Panorama de la poesía cubana. Siglo $X X$, La Habana, Letras Cubanas.

Chávez, Félix Ernesto, "La nueva poesía cubana: el cuestionamiento de una generación en ausencia”, 2008, en: Trujillo, María Cecilia (ed. y coord.), Lectores, editores y audiencia. La recepción en la literatura hispánica, Vigo, Academia Editorial del Hispanismo, pp. 93-97.

Dorta, Walfrido, 2002, "Estaciones, estados, documentos: panorama de la poesía cubana en los ' 80 y los '90 del siglo XX”, en: Anales de literatura hispanoamericana, No 31, págs. 17-38.

Espinosa, Norge, 2000, Las estrategias del páramo, La Habana, Ediciones UNIÓN.

Hangelini, Félix, 2006, La devastación (La imaginación de la Bestia), Valladolid, Fundación Jorge Guillén.

León, José Félix, 1999, Patio interior con bosque, La Habana, Ediciones UNIÓN.

Marimón, Javier, 2001, El gatico Vasia (cómo engañé al Súbito), Matanzas, Ediciones Aldabón.

Miranda, Michael H., 2003, En óleos de James Ensor, La Habana, Editora Abril.

Pintado, Carlos, 2008, Habitación a oscuras, Madrid, Vitruvio.

Riverón, George, 2008, Señal de vida, Miami, Bluebird Editions.

Simón, Nelson, 1993, El peso de la isla, Pinar del Río, Ed. Hermanos Loynaz.

Souza, Jorge (comp.), 2002, Heridos por la luz. Muestra de poesía cubana contemporánea, Guadalajara, Universidad de Guadalajara, México. 